\title{
Computer simulation the moldboard's surface in simplex system
}

\author{
Tojiddin Juraev ${ }^{1 *}$, Denis Voloshinov ${ }^{2}$, Rustam Xujakulov ${ }^{3}$, Abdurahim Qahharov $^{4}$, and \\ Dilorom Ubaydullayeva ${ }^{1}$ \\ ${ }^{1}$ Bukhara branch of Tashkent Institute of Irrigation and Agriculture Mechanization Engineers, \\ Tashkent, Uzbekistan \\ ${ }^{2}$ The Bonch-Bruevich St. Petersburg State University of Telecommunications, St. Petersburg, Russia \\ ${ }^{3}$ Karshi Engineering and Economic Institute, Karshi, Uzbekistan \\ ${ }^{4}$ Namangan Engineering Construction Institute, Namangan, Uzbekistan
}

\begin{abstract}
There are considered the tasks of computer simulation of moldboard's surface in the article. The proposed solution is required in educational, research, and production processes. The researches were carried out using the constructive geometric modeling methods and systems. Objects of computer simulation were chosen the computer models of a directory curve, generative lines, and a frontal contour which are elements of the working surface. The geometric models of working surface elements developed based on research results were implemented in AutoCAD and SIMPLEX systems. The proposed simulation models can reduce the design period, simplify the geometric parameters' setting and facilitate the work of designers.
\end{abstract}

\section{Introduction}

It is important to conduct engineering design based on information and communication technologies in a digital economy by using geometric modeling methods and systems. This is especially in demand in the process of designing complex technical surfaces, such as moldboards. Moldboards are one of the most common use and very geometrical complexity working organs of agricultural machines. Therefore, their geometric complexity requires developing the geometric models and algorithms for its implementation in computer-aided design systems, which is an urgent task for specialists. Many research and development projects have been proposed to develop moldboards, and several models and methods have been developed. In particular, they are considered fundamental in the following scientists' works: V.P.Goryachkin, L.V.Gachev, G.N.Sineokov, I.M.Panov, and others [1-4]. In Uzbekistan, the issue was partially handled by R.I.Baymetov, A.T.Tuhtaquziev, F.M.Mamatov [5], etc. In these works, traditionally, problems were solved based on analytical and experimental methods. However, the analysis of the essential parameters of working surfaces shows that many of these problems in nature are geometric, and use the geometric modeling methods in solving these problems gives effective results thanks to the work of geometric scientists S.M.Kolotov, N.F.Chetverukhin, V.E.Mikhailenko,

\footnotetext{
*Corresponding author: tojiddin_1968@mail.ru,
} 
S.A.Frolov, K.I.Valkov, V.S.Obukhova, D.V.Voloshinov, D.F.Kuchkarova, Sh.K.Muradov and others have been developed geometric models, algorithms, and methods for various engineering research areas. However, these developments are almost not used in research the working surfaces. If we consider that such developments are necessary for the application of computer-aided design, then the importance of this issue will become even clearer. The use of modern synthetic methods makes it much easier to solve these problems, its simplicity, and accessibility and significantly reduces the time, labor, and material costs for their solution, which is confirmed by the wide use of these methods [6-16]. The analysis carried out in subordinate design studios (for example, Main Specializing Design Studio "AgriMach") and research institutions (for example, Research Institute of Agriculture Mechanization "UzMEI," as well as at agricultural machinery enterprises (for example "ChirchiqAgriMach") in Uzbekistan, which are directly related to this problem, shows that the issues of developing moldboards based on computer modeling, taking into account the conditions of modern production, has not been sufficiently studied. The study aims to develop a computer modeling methodology for the development of moldboard type working organs by geometric modeling method [17-21].

\section{Materials and Methods}

As it is known, depending on the type of plowing performed and improving the technical and technological parameters of the moldboard and agricultural processing, the problem of choosing an optimal cross-section shape of the soil layer is solved. The developed geometric model of the soil layer wrapping scheme (Figure 1) clearly demonstrates that the shape and size of its cross-section, as input geometric data, are decisive in solving the problem under consideration, which confirms the importance of this model. However, when changing the geometric parameters, the solution of this problem using such a model, which is stationary, will become more difficult, since changing the shape of the cross-section will entail changing the parameters of the arable land and the moldboard, in which it is difficult to track changes in all parameters. In such cases, the model developed in the AutoCAD system can be exported to other computer modeling systems for conducting virtual research. Among such systems, it is necessary to distinguish the constructive geometric modeling system - SIMPLEX, which, as a "geometric machine," will allow us to easily explore objects by using geometric models based on geometric algorithms [19-20,24]. As noted above, the change in the shape of the cross-section of the formation occurs due to cutting the formation by various working organs: ploughshare, field sawn-off blade, preplough, angle grinder, various knives, etc. Therefore, the considered technological process, with the working bodies used in it as a complex system under study, has many relationships between the geometric parameters and technical and technological parameters associated with cutting. A reasonable choice of geometric parameters of these sections will have a positive impact not only on the technical and technological parameters of plowing, but also on the moldboard. The main relationships between the geometric parameters of the cut with the technical and technological parameters of the moldboard and the technological process were discussed in the corresponding author's works where were developed the static models. Naturally, the determination and justification of numerical values for specific relationships and parameters are performed by appropriate specialists based on fieldexperimental studies since these tasks go beyond the tasks of geometric modeling of the object under study. However, it is important to emphasize that the main input parameters of these sections in the cross-section of the soil layer are geometric parameters. Therefore, the development of a dynamic model for selecting geometric parameters of cross-sections will allow and facilitate the work of experts on the justification of parameters. 
Let's consider the problem of developing a dynamical geometric model of the optimized cross-section shape of the soil layer in the SIMPLEX system. It is known that the rectangle, as the main section of the soil monolith, is the base shape, so let's consider setting the geometric parameters of additional sections (Figure 1). To illustrate the advantages of this system, we will slightly complicate the building by changing the geometric parameters of the cross-section shape proposed in the corresponding author's works. Based on the conditions of geometric modeling, we divide these parameters into three categories: those related to the shape, position, and size of slices. To make the model universal, we first select general conditions for cutting by categories of geometric parameters. Let's distinguish the shape of the cut: along the cut line as a straight, curve, or combined (polyline), and according to the results of the cut as convex or concave, which will give them a single conditional definition of the start and endpoints of the cut. Visible position and, accordingly, the number cross-section on the sides of the rectangle are without crosssections, cutting to the intersection of the sides and one or more concave cross-sections around. We distinguish the size of the cross-sections by the starting, ending, and intermediate points that connect the cross-sections. Under these conditions, we can set various options for slicing.

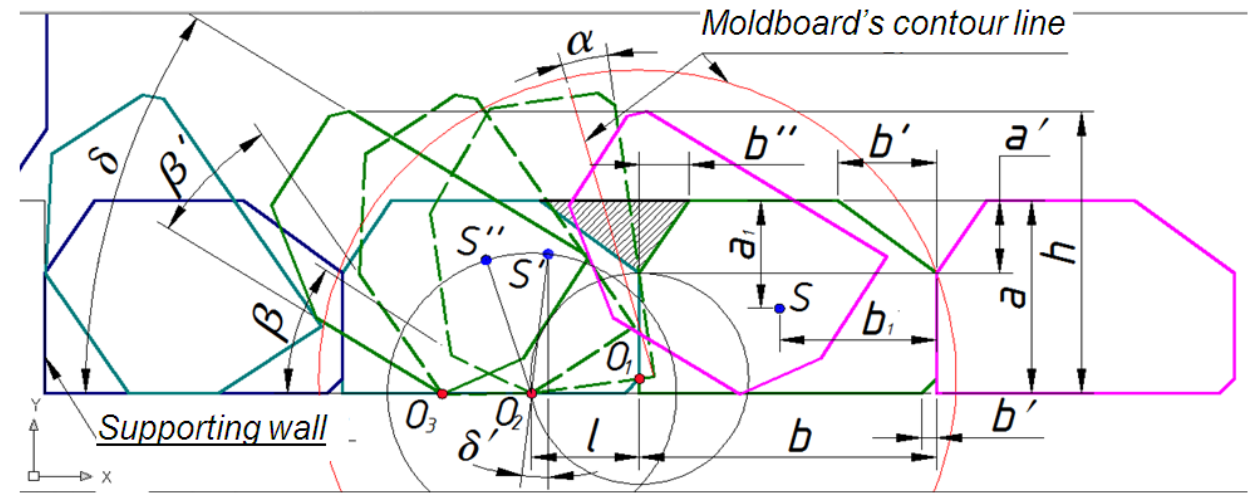

Fig.1. Giving the soil layer's cross-section

\section{Results and Discussions}

As an example, we can modeling a variant for setting cross-sections at the corners of the intersection of the sides of the rectangle $\mathrm{ABCD}$, sizes $\boldsymbol{a}$ and $\boldsymbol{b}$, discussed in the corresponding author works. Give cross-section $\mathrm{D}_{1} \mathrm{C}_{1}$ which called "lower ground cross," with the following parameters: 1) direct cross with convex shape; 2) is located on the intersection of the bottom and right sides; 3 ) cross with the starting point $\mathrm{D}_{1}$ as the length of the cutting belonging to the segment $\mathrm{AD}$, parameter, affiliation $\mathrm{C}_{5}$, and the endpoint $\mathrm{C}_{1}$ as the height of the cutting belonging to the segment $\mathrm{CD}$, with affiliation parameter $\mathrm{C}_{4}$ (Figure 2). The same geometric conditions are set for sections $C_{2} B_{2}$ and $A_{1} B_{1}$ with the technological names "upper field cut for weeding" and "upper furrow cut for reservoir turnover." When cutting the upper corners simultaneously with one working body, the parameter belonging to $C_{1}$ for points $A_{1}$ and $C_{2}$ is common as a technological condition. Set reference point of rotation $\mathrm{O}_{1}$ belonging to the side $\mathrm{AB}$ and the parameter $\mathrm{C}_{4}$ is equal to affiliation option affiliation point $\mathrm{C}_{1}$, as the top point of uncut formed in by front running moldboard is a supporting point of rotation of the reservoir cut away the ass going. 


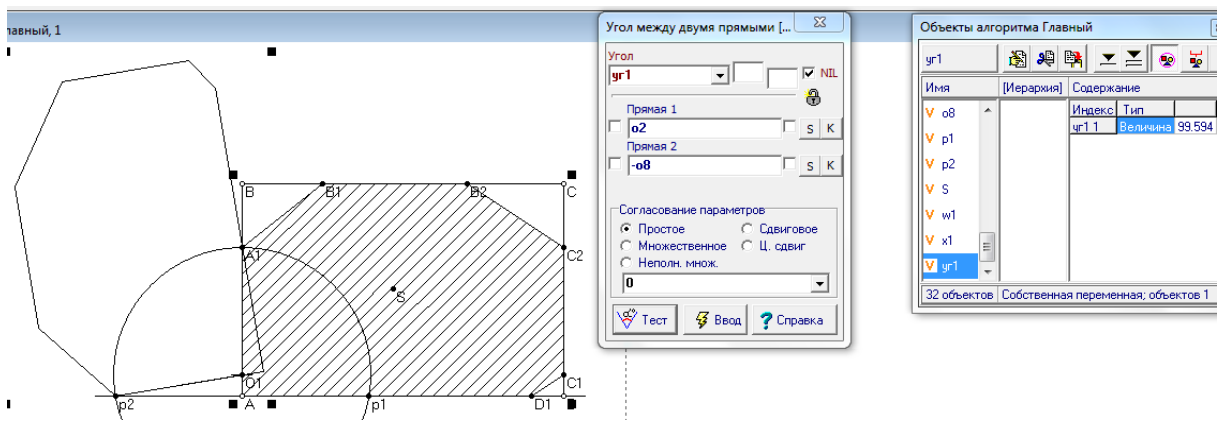

Fig.2. Dynamic model the cross-section cuttings in SIMPLEX.

Although specialists choose the final numerical values of the cutting parameters, their justification based on experimental studies, the current model will allow us to visually consider various options for the contour as a virtual test and select the necessary limits of values, controlling the parameters of the contour. By setting parameters by multiple relationship matching, we can consider various options for obtaining a cut; for example, consider a virtual study of the parameter "Depth of upper furrow cut" $\mathrm{A}_{1} \mathrm{~B}_{1}$ (Figure 3). Set the value $\mathrm{C}_{1}=\left(\mathrm{BA}_{1} / \mathrm{VA}\right)$ in the range from 0.1 to 0.5 with an interval of 5 , respectively, changing all the "simple" matches associated with the point $\mathrm{A}_{1}$ to "multiple."
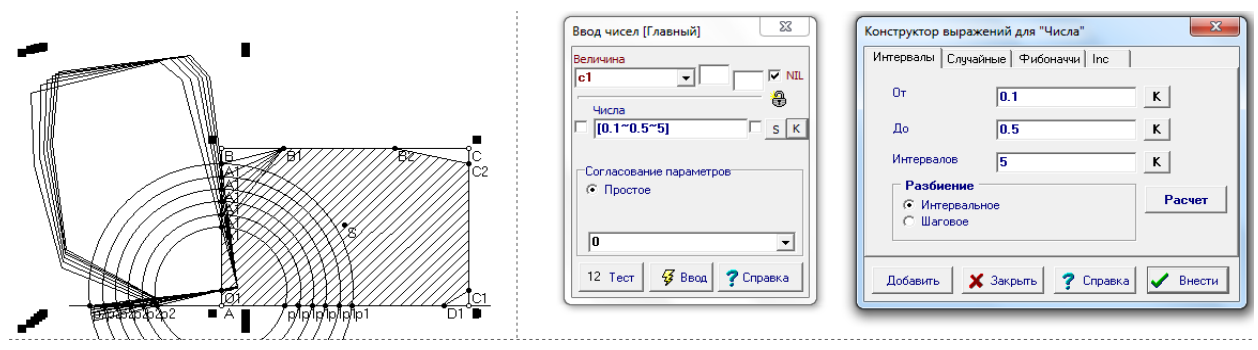

Fig.3. Virtual investigation of the output parameters of cross-section cuttings

In many engineering problems, determining the center of gravity of the object under study is solved [1-16], [23]. Studies conducted on this problem also show that one of the parameters to be determined for a given cross-section of the formation is the position of the center of gravity of its contour, especially when choosing different options for changing the contour, since this leads to a change in the position of the center of gravity, respectively. As it knows, according to the provisions of mechanics, the gravity vector is applied to the center of gravity, and it is always directed vertically. In this problem, this vector also determines the angle of withdrawal of the formation from the equilibrium position towards the furrow. Therefore, according to agrotechnical requirements, from the condition of not tipping the fallen layer of soil back into the furrow, it is necessary to wrap this layer at least until it leaves this position. Analysis of various forms of a cross-section of the formation (Figure 1) shows how changing the parameters of the section shape through various cutting options leads to a change in the position of the contour and the gravity vector. Moving the position of the center of gravity of the formation towards the arable land and reducing the angle of inclination of the balanced position of the contour allows us to reduce the rotation angle of the formation and, accordingly, reduce the force on its fall off. In the SIMPLEX system, the center of gravity is automatically determined by the "Barycenter" tool by setting the set of points that make up the contour (Figure 4). 


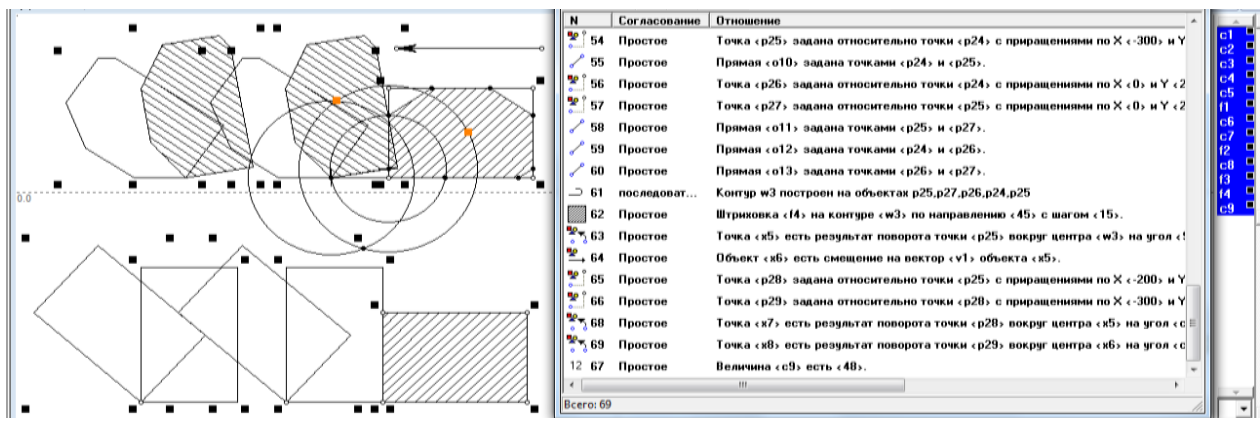

Fig. 4. Determining the center of gravity of a cross-section contour

To determine the line of a frontal contour of the blade: top, field, and furrow rifles, bind respectively to the lines of the trajectory of the upper point and the field side of the wrap seam, and corner of not scoring will fall off of the reservoir (Figure 5). If necessary, they can also be set as equidistant to these lines for the required distance. For ease of using the contour, parallel transfer to the vector $\boldsymbol{v 1}$, create an image of it, for which these lines are the prototype.

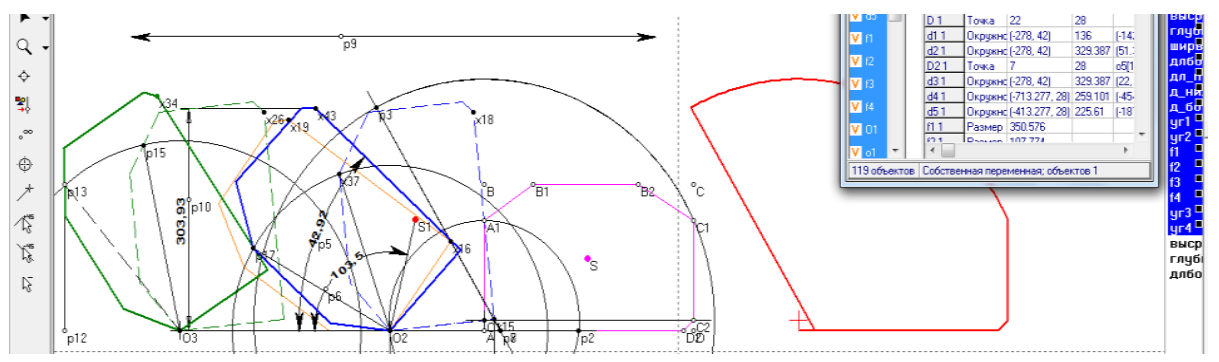

Fig.5. Determining the front contour lines of the moldboard.

\section{Conclusions}

The development of dynamic models in THE simplex structural geometric modeling system will allow you to visually and dynamically change geometric parameters, which will facilitate further development tasks, such as engineering calculation of dumps in CAE systems. Implementation of the developed geometric models and algorithms in the SIMPLEX system allows conducting virtual experiments on geometric parameters in conjunction with technical and technological characteristics, which shows the advantages and prospects of its use. In contrast to traditional design, where each project is implemented one-time, computer modeling has a reusable character, allowing one project to consider many options.

\section{Acknowledgements}

The correspondent author is grateful to the government of Uzbekistan, the leadership of Tashkent Institute of Irrigation and Agriculture Mechanization Engineers (TIIAME), Peter the Great St. Petersburg Polytechnic University (SPbPU), Bukhara Engineering-Technological Institute (BETI), St. Petersburg State University of Telecommunications (SPbSUT) and the Bukhara branch of TIIAME for an arrangement of conditions for conducting these researches, as well as to prof. D.F.Kuchkarova (TIIAME), prof. D.V.Voloshinov (SPbSTU and SPbPU) and prof. Sh.Dj.Imamov (Bukhara branch of TIIAME) for their consultations as a scientific supervisor. 


\section{References}

1. V.P.Goryachkin, Theory of soil destruction. Moscow: Kolos, pp. 369-81. (1965)

2. V.P.Goryachkin, Theory of the wedge. Moscow: Kolos, pp. 382-9. (1949)

3. G.N.Sineokov, I.M.Panov. Theory and calculation of tillage machines. Moscow: Machine building, p. 328. (1977).

4. L.V.Gachev, Theory of a landfill-mold boarding surface. Works Azov-Black Sea IMESH, Zernograd, 13 p. 317. (1961),

5. B.Mirzaev, F.Mamatov, I.Ergashev, H.Ravshanov, Sh.Mirzaxodjaev, Sh.Kurbanov, U.Kodirov and G.Ergashev. Effect of fragmentation and pacing at spot plugging on dry soils. E3S Web of Conferences 135, 01065 ITESE-2019 https://doi.org/10.1051/e3sconf/201913501065.

6. M.N.Lysych*, M.L.Shabanov and L.D.Bukhtoyarov,researchh of process overcoming obstacles by tillage tools. FORESTRY 2018. IOP Conference Series: Earth and Environmental Science 226 (2019) 012045. IOP publishing doi:10.1088/17551315/226/1/012045.

7. Hassnae Maher*, Rachid Moussadek, Abdelmjid Zouahri, Ahmed Douaik, Houria Dakak, Mouloud El Moudane and Ahmed Ghanimi, Effect of no tillage on the physicchemical properties of soils of the El Koudia region, Rabat (Morocco). E3S Web of Conferences 150, 0 (2020) https://doi.org/10.1051/e3sconf/20201500 EDE7-2019.

8. Yueming Wanga, Na Lia, Yunhai Maa, Jin Tonga, Wilhelm Pfleging, Jiyu Sun, Field experiments evaluating biomimetic shark-inspired (BioS) subsoil for tillage resistance reduction. https://doi.org/10.1016/j.still.2019.104432.

9. P.G.Svechnikov and I.P.Troyanovskaya, Tractor plough designing with specified tillage quality. Conference on Innovations in Agricultural and Rural development. IOP Conf. Series: Earth and Environmental Science 341 (2019) 012119 IOP Publishing doi:10.1088/1755-1315/341/1/012119.

10. Andrea Formato*, Domenico Ianniello, Francesco Villecco, Tony Luigi Leopoldo Lenza, Domenico Guida, Design optimization of the plough working surface by computerized mathematical model. Emirates Journal of Food and Agriculture.. 29 (1): (2017) pp. 36-44 doi: 10.9755/ejfa. 2015-10-918. http://www.ejfa.me/.

11. M.N.Lysych, Review of numerical methods for modeling the interaction of soil environments with the tools of soil tillage machines. 1399. doi:10.1088/17426596/1399/4/044014. Journal of Physics: Conference Series, (2019).

12. Z.Asaf, D.Rubinstein and I.Shmulevich. Determination of discrete element model parameters required for soil tillage. Soil and Tillage Research, 92, (1-2), January (2007), pp. 227-242. https://doi.org/10.1016/j.still.2006.03.006.

13. V.Ovsyanko, A.Petrovsky, The computer modeling of interaction between share moldboard surface of plough and soil J. Res. Appl. Agric. Eng., pp. 59 100. (2014).

14. James Barr, Jack Desbiolles, Mustafa Ucgul, John M.Fielke. Bent leg furrow opener performance analysis using the discrete element method. Biosystems Engineering. 189, January (2020), pp. 99-115.

15. D.V.Voloshinov, Theory of automation of design of objects and processes on the basis of methods of constructive geometric modeling. Annotation of Dissertation:SPb.: SPbSPU, p 33. (2010).

16. D.V.Voloshinov. Constructive Geometric Modeling. Theory, Application, Automatization: Monograph. / Lambert Academic Publishing. Saarbrucken, p. 355. (2010).

17. T.Kh.Juraev, Conceptual Designing of Mould Board's Surface by Geometrical Modeling. American Journal of Mechanics and Applications. 5, (4), (2017), pp. 28-33. 
doi: 10.11648/j.ajma. 20170504.11. ISSN: 2376-6115 (Print); ISSN: 2376-6131 (Online). http://www.ajmechanics.org/archive/621/6210504

18. T.Kh.Juraev, Creating the Geometric Database for Product Lifecycle Management System in Agricultural Engineering. ICISCT 2017. Applications, Trends and Opportunities. 2-4 November 2017, TUIT, Tashkent, Uzbekistan. IEEE Catalog Part Number: CFP17H74-CDR, ISBN: 978-1-5386-2167-7.

19. T.Kh.Juraev, Decision Maintenance Management Problems in Agriculture Engineering by Constructive Geometric Modeling Methods. Maintenance Management. Edited by Fausto Pedro García Márquez and Mayorkinos Papaelias. London, United Kingdom. pp. 23-37. (2017)

20. T.Kh.Juraev, Computer modeling the moldboards' surface in AutoCAD system. IOP Publishing. Materials Science and Engineering, 883, CONMECHYDRO - 2020, 012156, doi:10.1088/1757-899X/883/1/012156. https://iopscience.iop.org/article/10.1088/1757-899X/883/1/012156.

21. T.Kh.Juraev, D.V.Voloshinov, Geometric modeling laboratory as an engineering infrastructure in the digital economy. IOP Publishing. Materials Science and Engineering, 869, SMART CITY, FORM-2020. Number 2, July 2020, 022037, doi:10.1088/1757-899X/869/2/022037.

22. T.Kh.Juraev, S.Norov, F.Musulmanov, Study of the Parameters of the Planner with a Screw Working Body. Direct Torque Control Strategies of Electrical Machines. http://dx.doi.org/10.5772/intechopen.93308.

23. Ismatovna, T. D., Ikramovich, K. A., Djaxanovich, I. S and Farhodovich, M. F. Dynamic Modeling of Vibrating System N-S Component Parts Which of That the Mobile Machines for Fast Acting Pneumatic Actuator with Self-Damping. In International Conference on Information Science and Communications Technologies: Applications, Trends and Opportunities, ICISCT 2019. Institute of Electrical and Electronics Engineers Inc. (2019).

24. D.V.Voloshinov. SIMPLEX, Automation system for geometric calculations and modeling. St.Petersburg, https://voloshinov.ru/docs/dvv_simplex_1997.pdf. (1997). 